\title{
Research on IETM Development Technology for Industry Equipment
}

\author{
Song Xiangjun, Deng Daquan and Li Wanling ${ }^{a}$ \\ Ordnance Technology research institute. Shijiazhuang Hebei, China \\ azyh8282180@sina.com
}

Keywords: industry equipment; IETM; informationization; standard

\begin{abstract}
Using for reference international advanced standard and combining with Chinese industry equipment technology characteristic, modernization equipment IETM development technology criterion was established. Current equipment IETM integration development flatform was developed handling IETM key technology for demand of equipment use and maintenance guarantee to improve efficiency of Chinese industry equipment use and maintenance guarantee.
\end{abstract}

\section{Introduction}

In order to improve use and guarantee benefit of industry equipment, each country of the world attaches importance to informationization development for equipment use and maintenance guarantee very much while it upgrades informationization level for development actively. Overseas developed country developed many information systems for equipment use and maintenance guarantee to improve its use and maintenance guarantee efficiency supported by information technology. Informationization guarantee for industry equipment became an inexorable trend of equipment use and maintenance guarantee development already.

Interactive electronic technical manual (IETM) synthetically uses computer multimedia technology, database technology and network technology to organize technology data such as equipment configuration, fault maintenance and operation maintenance etc organically with correlated standard, and display information such as character, picture, audio frequency and video frequency etc on electronic screen with optimum mode. It can consult them with interactive mode, and display the information needed by maintenance technology personnel and equipment operation personnel to improve efficiency of the equipment use and secure.

\section{Internal and Overseas Present State of IETM Technology}

Overseas Present State of IETM Technology. From last century 90, the department of defense of America, North Atlantic Treaty Organization and international crganization for standardization had established a series of IETM technology standard and criterion in order to regulate IETM exploitation technology. It includes:

- MIL-PRF-87268A Performance Specification, Manuals, Interactive Electronic Technical General Content, Style, Format and User - Interaction Requirements 1995

- MIL-PRF-87269A Performance Specification, Data base, Revisable - Interactive Electronic Technical Manuals 1995

- MIL-PRF-28001C Performance Specification Markup Requirements and Generic Style Specification for Exchange of Text and Its Presentation 1997

- MIL-STD-40051A Department of Defense standard Practice: Preparation of Digital Technical Information for Multi-output Presentation of Technical Manuals 1999

- MIL-HDBK-511 Department of Defense standard Handbook for Interoperability of Interactive Electronic Technical Manuals (IETMs) 2000

- MIL-STD-2361A Department of Defense Interface Standard Digital Publications Development

- ASD S1000D International Standard of Adopting CSDB to Eestablish Technic Document 2008 
In all the diversified IETM technology standards mentioned above, ASD S1000D standard put forward by Aerospace and Defence Industries Association of Europe (ASD) was widely applied in the field of military affairs and civilian in Europe country because of its strongpoint. Currently, America industries speciality association standardization institution, such as electric and electron engineers association IEEE, also chooses the industries standard.

Except IETM standardization technology, research on ITEM technology also involves information numerralization technology, information resource format conversion, database technology, network technology and integration of IETM and other systems (such as fault diagnosis system, expert system and teaching and training system.

Present State and Requirement Analysis for Chinese Industry Equipments IETM Technology. Industry equipments in China were usually manufactured by many units, and exploitation for IETM would be a quite huge workload and needing many units coadjutant assignment. Although other countries had mature IETM technology standard and exploitation for IETM had brought into some equipment production process, we could not completely copy overseas mode because of the difference of equipment production character, management mode and IETM development level in China form occident countries. So the exploitation application requirement of IETM for industry equipments maintenance supply was analyzed and the IETM exploitation organizational implementary means fitted for Chinese industry equipment character according to actual instance in China.

The research on IETM in China was still in the underway phase, at present there had not IETM national standards and military standards to be depended on. To ensure the exploitation and manufacture for industry equipment guarantee IETM to be established in upper technology jumping-off point, it must be established in overseas advanced IETM technology standards and the research on Chinese industry equipment IETM exploitation technology standards to standardize and guide Chinese industry equipment IETM exploitation and application.

In all kinds of IETM correlative international standards, ASD S1000D standard put forward by Aerospace and Defence Industries Association of Europe was widely applied in the field of military affairs and civilian in Europe country because of its strongpoint, so it could be traded as the most worth referenced technology standard for Chinese industry equipment IETM exploitation.

\section{Industry Equipment IETM Exploitation Technology Project}

\section{Basic Object.}

- establish Chinese industry equipment IETM exploitation technology criterion and integrated exploitation platform, IETM established by the technology criterion and integrated exploitation platform could realize advanced design thinking of data compatibility and information reusability put forward by international current standard.

- the IETM system exploited by the technology criterion and integrated exploitation platform could utilize modes such as hyper text interlinkage and full text searches etc to allow the users to search and obtain equipment guarantee information resources, and it could adopt manifold forms such as letter, image, video frequency and audio frequency etc to intensify intelligibility of equipment guarantee technology information. Accordingly it could advance equipment maintenance efficiency, shorten equipment guarantee training time and reduce equipment guarantee expense.

- the IETM system exploited by the technology criterion and integrated exploitation platform could solve large industry equipment paper technology information rapid bulgy problem and reduce the publish, update, storage and overhead expense of industry equipment technology information to efficiently reduce the full-life cycle guarantee expense of industry equipment.

\section{Key Technology.}

\section{IETM Standardization Technology}

ASD S1000D standard put forward by Aerospace and Defence Industries Association of Europe is an international standard of adopting current resource database to establish technology document, and it was upgraded and maintained by expert organization. Its technology information was 
organized as neutrality format, used data module concept and its currency was very good. IETM established by the standard could change for information form different platforms and systems and issue information with manifold mode.

The research content of ASD S1000D standard was very abroad, it included generative rule of IETM information, expression and usage of information, management of information and integration and issue of information. The standard put forward two kernel concepts, Data Module (DM) COMMON Source Data Base (CSDB). So the two kernel concepts were realized S1000D standard was also realized.

The research content of ASD S1000D standard also included digitized issue flow. And the flow included constituting operation rules, confirming issue deepness and bound, constituting requirement list of Data Module, compiling Data Module and confirming issue mode and publication facture etc.

\section{IETM Creative Technology}

The main sources of huge technology information included in equipment IETM were design explanatory memorandum, fault handbook and usage handbook etc. The information were from engineering data produced by CAD/CAM or PDM/ERP information management systems. It could digitize information data of handbook and document from photograph scan and letter recognition etc computer technology.

In order to produce IETM, the text information of a suit of technology document would be carve up a great deal of information units. The data were labeled neutrality format by Extensible Markup Language (XML), the data would be storaged into Data Module with Document Type Definition (DTD) or XML Schema configuration, and the illustration, audio frequency and video frequency etc information were storaged into separate document with S1000D standard. This was doing standard format conversion for all equipment numeralization information in the collection.

All Data Module and multimedia information objects were storaged into CSDB with S1000D coding standard to be convenient for information searches and reuse etc management function. CSDB was storage place for all items and all technology information.

IETM litmusless memorizer shouldered by document memory system, network server or database only stored information data needed by a certain item. In order to make IETM users view include technology information in many different CSDB databases, IETM litmusless memorizer was adopted to separate CSDB data fountainhead and end user view.

All data modules included in the IETM litmusless memorizer showed as XML data format, the data modules generated from CSDB, and were used for users while formatted by Extensible Style-sheet Language (XSL).

\section{Aan Exploitation Example for a Certain Engine IETM System}

The industry engine was developed by China itself in 21 century, and in order to reduce difficulty of training and maintenance job for the engine and generate sustaining engine maintenance guarantee capability rapidly, the engine IETM system was exploited, and it had basic functions which were shown as follows.

- equipment conformation and principle assistant teaching: using letter explanation, work schematic diagram, electron circuit diagram, signal flow gragh, audio frequency and video frequency etc forms to assist teaching and training for equipment conformation and principle.

- equipment representative fault analysis: using fault phenomenon to present process of finding, analyzing and judging fault, link idiographic fault repair operation modules and present idiographic means of fault repair.

- equipment repair operation training: presenting idiographic repair operation means, approach and requirement for each repair item.

- equipment repair training scheme quekry: including repair institution repair training content, repair training scheme examination standard of all levels. 
- equipment technology maintenance operation training: using letter, image, video frequency and audio frequency etc multi-forms to show information, such as content, occasion, assignment divide, means, approach and technology requirement etc, of equipment maintenance to help equipment maintenance operation and training.

- equipment repair curriculum vitae information: including curriculum vitae information management such as equipment leaving factory information, equipment boot-strap usage information, equipment maintenance information and equipment repair information etc.

- equipment management bylaw and equipment repair technology standard: including technology standard electronic document relating to equipment management and repair operation, and providing index and quekry function.

- According to modularization design thinking based on strong cohesiveness and weak coupling, the exploitation for the engine IETM system was divided to data module inventing subsystem, multimedia inventing subsystem, CSDB management subsystem, fault diagnosis subsystem and technology information display subsystem.

\section{Summary}

Current industry equipment IETM exploitation technology criterion imported advanced current resource database and data module concepts for Chinese industry equipment IETM exploitation, and it adopted XML neutrality data format and XML Schema storage configuration. IETM established according to the criterion could realize data compatibility and information reusable advanced design thinking put forward by international IETM standard.

\section{References}

[1] Beijing Spaceflight Test and Control Technology Exploitation Company. Appliction and the Feature of IETM. Aviation ManufactureTechnology, 2010,13: 100 101.

[2] Su Wei. The Thinking of Research and Application for IETM. Aeronautic Standardization \& Quality. 2009,2: 33 36.

[3] Zhu Ning. The Research and Development of IETM. Weapon Equipment Automatization. 2008,27: 11.

[4] Gao Wanchun, Zhu Xingdong, Song Jianhua etc. Research and Practice of IETM Authoring According to S1000D. Control \& Management. 2003,3: 1 3.

[5] Li Zongliang. Research on IETM System Technology Based on the S1000D Specification. A Dissertation Submitted to Guang University of Technology for the Degree of Master of Engineering. 2005: 30 38.

[6] Hu Yaoguang, Meng Xiaohua, Li Chen. Design and Implementation of Data Module of IETM system Based on S1000D Specification. Computer Engineering and Design. 2009,30(13): 3222 3224.

[7] International Specification for technical publications- S1000D [z]. Issue 3.0,2007.

[8] Chris Wood. XML IETMs [C]. Granuda: Europe 99, 1999.

[9] Jiang Lili, Li Zongliang, Wu Yongming etc. PLCS-Based IETM Feedback Mechanism. COMPUTER SCIENCE FOR DESIGN AND TECHNOLOGY. 2005.

[10] Jiang Lili, Li Zongliang, Wu Yongming etc. Introduce PLCS to Support product information in CALS. COMPUTER SCIENCE FOR DESIGN AND TECHNOLOGY. 2005.

[11] E. L. Jorgensen. Proposed Web-based Architecture for the Interoperablity of Naval Aviation IETMs. Technical Report CDNSWC-TSSD-98-10. August 1998.

[12] Tri-Service Working Group for Interactive Electronic Technical Manuals. Manuals, Interactive Electronic Technical: General Content, Style, Format and User-Interaction Requirements. October 1, 1995. 